\title{
Working through it
}

\author{
Stephen Hancocks OBE \\ Editor-in-Chief
}

The BDJ Upfront section includes editorials, letters, news, book reviews and interviews. Please direct your correspondence to the News Editor,

Kate Quinlan at k.quinlan@nature.com. Press releases or articles may be edited, and should include a colour photograph if possible.

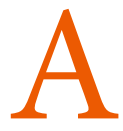
s dentists we are very practical people. The response to a workplace, office or practice which finds itself with accumulating stacks of books, journals or papers depends on who is in charge. A civil servant will put in a request for a larger office, a general medical practitioner will ask the practice manager to order two new oak bookcases, while a dentist will wait until the weekend, get timber and a saw and put up some shelves.

It has been, and continues to be, fascinating to experience the evolving response to the coronavirus pandemic through the flow of thoughts, proposals for content and submissions. Although I write flow it has been a flood, a deluge, at times what has seemed like an almost unstoppable water cannon of material. There are very discernible patterns and some fairly predictable reactions but one theme which comes through for me is that very practical element of our reaction to a problem; solving it by action, ingenuity and often just plain dogged determination. The difficulty arises in deciding what is worth publishing and when. By worth, I mean value. What is of value to you the reader when you are struggling to make sense of the uncertainties thrown up by this very rare situation?

A good example is contained in the energies put into devising new ways of capturing aerosols that may include viruses or virus particles during treatment procedures. Clever dentists have been collaborating with knowledgeable engineers and coming up with a variety of sometimes weird and often wonderful contraptions. Early on in the pandemic we included some information on the initial designs but that merely opened the floodgates. It seemed as if every other dentist had ransacked their shed during the prolonged lockdown and come up with Apollo-13 like possible solutions to enable safe re-entry. The questions we then had to ask were; this is an interesting concept and a praiseworthy enterprise but how good is it really? How well does it compare with other methods - masks, extraction equipment, air filters systems etc? Is it commercially available? If yes (and probably not at this stage while it is in a laboratory - or a garage) what does it cost and how difficult is it to fit/implement? Is it a 'so what, two guys have had an idea' and is it a waste of time reading this if none of the above is a positive for the reader?

The conclusion has been given to potential authors: you need to have a research paper on this or any other subject and then submit it. We will then put it through the expedited peer review process that we have set up for corona-related content (which is both the it in the $B D J$. That reputation has been built not on speed but by robustness.

Which brings me neatly to some thanks. Our reviewers have been exceptional in turning round papers so quickly and our authors have also been swift in returning modified work and in proof reading within very tight timelines. Without this co-operation we would have not been able to have brought you so much on the effects of the pandemic on dentistry so soon in terms of papers, articles and letters. We would also like to thank for their understanding, the many authors whose work we have had to turn down for reasons of duplication or overlap with previously accepted content from others. Troubled students, trainees, redeployed

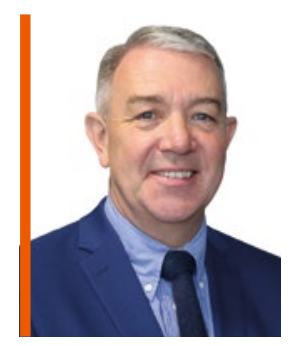

\section{'What is of value to you the reader when you are struggling to make sense of the uncertainties thrown up by this very rare situation?'}

purpose and value of the $B D J$ ) and then the whole world can answer the questions above. If you don't have credible research then we are not the place to publish.

Another often asked question in the recent surge, we have been receiving between three and four times our usual numbers of submissions, is about speed. 'How quickly can you get this published?' We have two issues a month - more than any other major dental journal in the world - but the content of each takes time to peer review, agree upon, collate, lay-out, proof read, prepare for print (and dispatch) and for posting online. In short, if you want the world to read about it by tomorrow morning we are not the place to come; post it on a website, any site. 'But' say the authors 'we want the reputation of having colleagues and private practitioners fall particularly into this category as well as authors on teledentistry, online surveys of dentists' opinions on coronavirus, the value of webinars and much else.

Included in this issue you will see Evidence-Based Dentistry which Editor, Professor Liz Kay has managed to bring together with an impressive host of contributors summarising the scientific literature from other sources on the pandemic and its effects. Our aim collectively within the $B D J$ Portfolio is to continue to bring you the best science, the most cogent current debate and the knowledge to aid your survival and provide the best patient care so that we, like you, can work through it.

https://doi.org/ 10.1038/s41415-020-1791-4 